\title{
Winter synoptic-scale variability over the Mediterranean Basin under future climate conditions as simulated by the ECHAM5
}

\author{
Christoph Cornelius Raible • Baruch Ziv • \\ Hadas Saaroni • Martin Wild
}

Received: 7 January 2009/Accepted: 28 September 2009/Published online: 15 October 2009

(C) Springer-Verlag 2009

\begin{abstract}
Changes of the winter climate in the Mediterranean Basin (MB) for future A2 conditions are investigated for the period 2071-2100 and compared with the control period 1961-1990. The analysis is based on timeslice simulations of the latest version of the ECHAM model. First, the control simulation is evaluated with reanalysis data. The emphasis is given to synoptic and large-scale features and their variability in the MB. The model is found to be capable of reproducing the main features of the $\mathrm{MB}$ and southern Europe in the winter season. Second, the A2 simulation is compared with the control simulation, revealing considerable changes of the synoptic variability. Focusing on the synoptic spatio-temporal scale aims to unfold the dynamic background of the
\end{abstract}

Electronic supplementary material The online version of this article (doi:10.1007/s00382-009-0678-5) contains supplementary material, which is available to authorized users.

\section{C. Raible $(\square)$}

Climate and Environmental Physics, Physics Institute,

University of Bern, Sidlerstrasse 5, 3012 Bern, Switzerland

e-mail: raible@climate.unibe.ch

\section{C. Raible}

Oeschger Centre for Climate Change Research,

University of Bern, Bern, Switzerland

B. Ziv

Department of Natural Sciences, Open University,

Tel Aviv, Israel

H. Saaroni

Department of Geography and the Human Environment,

Tel Aviv University, Tel Aviv, Israel

M. Wild

Institute for Atmospheric and Climate Science ETH,

Zurich, Switzerland climatic changes. The Mediterranean cyclones, which are individually detected and tracked, decrease by $10 \%$ in the Western Mediterranean (WM) whereas no significant change is found in the Eastern Mediterranean. The cyclone intensity is slightly reduced in the entire region. To understand these changes, the underlying dynamical background is analyzed. It is found that changes in baroclinicity, static stability, transformation from eddy kinetic energy to kinetic energy of the mean flow and stationary wave activity are significant in particular in the WM and the coastline of North Africa. The reduction of cyclonic activity severely impacts the precipitation mainly in the southern part of the WM.

Keywords Cyclones - Eddy kinetic energy ·

Mediterranean $\cdot$ A2 scenario

\section{Introduction}

All global climate models, applied to emission scenarios of the twenty-first century, project a general warming (IPCC 2001). Besides the Arctic and the Antarctic, the IPCC (2007) suggests that the Mediterranean Basin (MB) is another key region of high anthropogenic climate impact, in particular on the hydrological cycle in winter, the rainiest season of the region (HMSO 1962; Gibelin and Déequé 2003; Lionello et al. 2006; Giorgi and Lionello 2008).

The MB is located close to the subtropics (partly in the subtropics) and is heavily influenced by the surrounding regions and possibly by long distance teleconnections. Obviously, the North Atlantic, located upstream, has an important impact on the climate of the MB, by, e.g., cyclones traveling into the MB (Raible 2007), or blocking events (Martin et al. 2004), which prevent cyclones in the 
western part of the MB and lead to polar intrusions further downstream in the eastern part ( $\mathrm{Ziv}$ et al. 2006). Other factors affecting the MB are the North Atlantic Oscillation (Jacobeit et al. 2003) and the West Atlantic-East Russia oscillation (Krichak and Alpert 2005). In addition to the above mentioned mid-latitude factors, the MB is affected by episodes of tropical-extra-tropical interactions. These include the Red-Sea trough (Dayan et al. 2001), the North African Sharav cyclones (Alpert and Ziv 1989), and tropical plumes (Ziv 2001; Knippertz 2005). Tropical plumes are mainly active in the winter season (Rubin et al. 2007). Moreover, there are indications of a possible influence of El Niño Southern Oscillation (ENSO) on the MB (Price et al. 1998; Brönnimann 2007), which is, however, still under debate.

A hint that the MB is sensitive with respect to the hydrological cycle is given by recent changes in the past decades, based on observations. Alpert et al. (2002) found a negative trend in rainfall for the last 60 years over the majority of the MB, and suggested that this is part of global climate change. This negative trend in the MB and southern Europe is clearly seen in the precipitation difference between the mean of the period 1978-2007 and 1949-1978 (not shown).

A major factor for generating precipitation in the MB is the cyclonic activity. Raible (2007) suggested a connection between the occurrence of extreme cyclones (either generated in the MB or penetrating from the North Atlantic) and precipitation events in Southern Europe (including the MB). This relation was stable in a period of cold climate conditions in the past (Raible et al. 2007). For the Eastern Mediterranean (EM) polar intrusions play an important role (Saaroni et al. 1996). They are accompanied by a deep upper-level trough and are associated with low-level cyclogenesis (Alpert and Reisin 1986). Observations show that cyclones, which are formed via this process, cause intense precipitation events in the EM (Alpert and Reisin 1986).

Recently, several attempts were made to assess future changes of the rainfall regime over the MB. The IPCC (2007), based on an ensemble of the climate models, and Lionello and Giorgi (2007), using the regional climate model (RegCM), project an increase in winter rainfall over Europe and the northern coast of the MB and decreased precipitation over the southern and eastern MB for the period 2071-2100. Lionello and Giorgi (2007) explain these trends by an increase in cyclone activity over Western Europe accompanied by a reduction of cyclonic activity within the MB. Krichak et al. (2007) using the $\mathrm{RegCM}$ projected a reduction of the winter precipitation over the eastern MB.

The purpose of this study is to assess the importance of possible future changes in synoptic-scale features for the hydrological cycle in the MB. Due to the complexity of the terrain in this region and because rainfall changes involve a wide range of scales, it is necessary to study possible future changes by highly resolved model simulations. To that end we use simulations of a higher resolution model-the ECHAM5 (Roeckner et al. 2003). The simulations are performed for two periods: a control period from 19611990 to evaluate the model's ability to realistically simulate the climate conditions, and the period 2071-2100, based on the IPCC A2 scenario, which offers the most extreme potential changes, due to the highest expected anthropogenic forcing being applied. To better classify the changes of the A2 scenario we additionally analyzed a second set of time slice experiments including B2 scenario for the period 2071-2100 however with a slightly different model setup (see Sect. 2 and supplementary material). The main focus of this study is on synoptic-scale features and extreme events, assessing the following variables:

- the potential for cyclone formation by baroclinicity and static stability,

- the frequency and intensity of cyclones in the MB,

- the eddy kinetic energy transformation from the mean flow,

- the stationary wave activity,

- polar outbreaks, and

- precipitation.

The outline of the study is as follows: The database (model simulations and reanalysis data) and methods are introduced in Sect. 2. Section 3 evaluates the control simulation using a reanalysis data set. In Sect. 4, the A2 simulation is compared with the control simulation to assess possible future changes. Finally, the results are discussed and major conclusions are highlighted in Sect. 5.

\section{Data sets and methodology}

The study is based on model and reanalyses data. The main tool is the fifth version of the European Centre model of Hamburg (ECHAM5; Roeckner et al. 2003). This atmospheric general circulation model (GCM) is based on the primitive equations and uses temperature, logarithm of pressure, specific humidity, cloud-water mixing ratio (liquid and solid), vorticity, and divergence as prognostic variables. The horizontal resolution of this spectral model is T106, corresponding to a longitude-latitude grid of approximately $1.125^{\circ} \times 1.125^{\circ}$ and 31 hybrid sigmapressure levels in the vertical with the uppermost level at $10 \mathrm{hPa}$.

Two time-slice simulations are performed with ECHAM5. The control simulation ('Ctrl simulation', hereafter) for the period 1961-1990 is forced by observed 
sea surface temperatures (SSTs) from the HadISST data set (Rayner et al. 2003) and the observed evolution of $\mathrm{CO}_{2}$, other well-mixed greenhouse gases, and ozone. The future scenario simulation (A2) for the period 2071-2100 is forced by the IPCC A2 scenario (IPCC 2001) and uses SSTs from a coupled model simulation generated with HadCM3 by the Hadley Centre (Rowell 2005). To provide a broader overview of possible changes, a second set of time-slice simulations is analyzed, also containing a simulation for the period 2071-2100, but with the less extreme B2 scenario (IPCC 2001) described in the supplementary material. This second set is performed with the same setup except that the ECHAM5 has a reduced vertical resolution of only 19 sigma-pressure levels. More details about both experimental setups are described in Rowell (2005) and Christensen and Christensen (2007).

To evaluate the model, the Ctrl simulation is compared with reanalysis data from the ECMWF for the period 1961-1990. Note that reanalysis data are thought to be an optimal estimate of observations. The reanalysis data set ERA40 is provided by ECMWF generated by their forecasting system at a horizontal resolution of T159 $\left(1^{\circ} \times 1^{\circ}\right)$ and 60 vertical levels (Uppala et al. 2005). The data is interpolated to a $1.125^{\circ} \times 1.125^{\circ}$ grid to be comparable with the ECHAM5 resolution. 6-hourly data as well as seasonal means for winter (DJF) are used for the analysis. The region is the $\mathrm{MB}$, covering the domain $25^{\circ} \mathrm{N}-55^{\circ} \mathrm{N}$, $10^{\circ} \mathrm{W}-45^{\circ} \mathrm{E}$ (Fig. 1). Additionally, for specific purposes, areas adjacent to the study region are analyzed.

To characterize cyclonic activity in the MB, two different methods are used. One is the classical Eulerian measure, the so-called dynamic storm track, which is defined as the 2.5-6.5 days bandpass filtered standard deviation (Stdd) of the 500-hPa geopotential height (gph; Blackmon 1976). The filtering restricts the storm track to

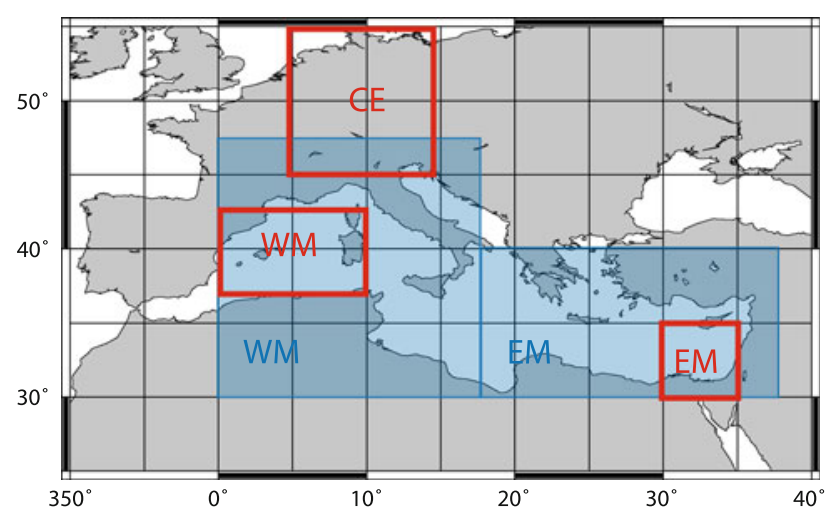

Fig. 1 The study region and centers of interest $(r e d)$ : Central Europe $(C E)$, Western Mediterranean $(W M)$, and Eastern Mediterranean $(E M)$. The shaded areas in blue are used for the cyclone statistics in the WM and EM, respectively the characteristic time scale of synoptic cyclones; however, a considerable amount of this synoptic-scale variability is related to high pressure systems and large-scale waves. The second is a state-of-the-art cyclone detection and tracking technique (Blender et al. 1997; Raible and Blender 2004). Low pressure systems are identified as minima of the 1,000-hPa gph field within the eight neighboring grid points. The mean minimum gradient in an area of $(1,000 \mathrm{~km})^{2}$ must exceed at least $20 \mathrm{gpm} / 1,000 \mathrm{~km}$. The minima are connected with a next neighborhood search within $1,000 \mathrm{~km}$ in $24 \mathrm{~h}$. To neglect weak and unrealistic minima, we require a minimum life-time of $24 \mathrm{~h}$ and a mean minimum gradient of $30 \mathrm{gpm} / 1,000 \mathrm{~km}$ once in the life-time of the cyclone. Note that the method has been compared with other methods using different reanalyses showing that the winter cyclones are detectable with this method in the MB (Raible et al. 2008).

To gain further insight into the dynamics of the MB on synoptic time scales additional variables are investigated. The maximum Eady growth rate $\sigma_{\mathrm{BI}}$ (Eady 1949; James 1994) is associated with the most unstable wave in the Eady model and describes the baroclinic production of transient eddies.

$\sigma_{\mathrm{BI}}=0.31 \frac{f}{N} \frac{\partial|v|}{\partial p}=0.31 \frac{1}{T}\left(\frac{1}{g \theta} \frac{\partial \theta}{\partial z}\right)^{-0.5}|\nabla T|$,

where $f$ signifies the Coriolis parameter, $N$ the Brunt-Väisällä frequency, $|v|$ the wind speed, $p$ the pressure, $T$ the temperature, $g$ the gravitational acceleration at sea level and $\theta$ the potential temperature. Thus, the growth rate depends on two factors: the horizontal temperature gradient, and therefore the vertical shear of the horizontal flow, and the static stability. Additional analysis of the static stability helps to separate the two factors (Walland and Simmonds 1999; Raible 2007). The three dimensional $\mathbf{E}$-vector is measure of eddy activity and describes the interaction of transient eddies with the mean flow (Hoskins et al. 1983; Trenberth 1986). The horizontal components of the $\mathbf{E}$-vector are related to the horizontal orientation of the eddy axes (Hoskins et al. 1983), and in the version of Trenberth are nearly parallel to the local group velocity of the transient waves and are therefore related to the energy flux. The vertical component describes the westward tilt with height of eddies and gives a qualitative indication of the vertical propagation of eddy activity. The scalar product of the horizontal $\mathbf{E}_{h}$-vector and the deformation vector D of the time mean flow describes the local production of eddy-kinetic energy (Mak and Cai 1989). They found that the local production of eddy-kinetic energy can be generated by both stretching and shear deformation of the mean flow. In the case that $\mathbf{E}_{h} \cdot \mathbf{D}$ is negative/positive, eddy kinetic energy is transformed to/from kinetic energy of the mean flow. In the current study the $\mathbf{E}_{h}$-vector as well as 
$\mathbf{E}_{h} \cdot \mathbf{D}$ are bandpass filtered with the same filter of Blackmon (1976) to restrict the analysis on synoptic-scale variability.

But not only transient eddies are relevant for the MB, stationary waves are also important. Therefore, we investigate the three dimensional $\mathbf{F}_{s}$ vector (Plumb 1985), which is the flux of the stationary wave activity and a generalization of the Eliassen-Palm flux in three dimensions. In a westerly flow convergence of the $\mathbf{F}_{s}$ vector in the upper troposphere implies dissipation of stationary waves, whereas its divergence implies production of stationary wave activity, e.g., by orography, diabatic heating, or transient eddy forcing. The horizontal components are parallel to the local group velocity and therefore to the energy flux.

To assess future changes, the Ctrl and A2 experiment are compared by showing differences. To test the statistical significance (at the 5\% level) of mean differences the Student's $t$ test is applied; for variance (standard deviation) an $F$ test is used (Wilks 2006).

\section{Model evaluation for the control period: 1961-1990}

In this section, the model simulation for the control period 1961-1990 is evaluated using ERA40 reanalysis data, referred to as 'observations'. The focus is on the region of interest, i.e., the $\mathrm{MB}$ and its surrounding regions.

\subsection{Mean fields}

To get a first order feeling of the model's ability in simulating the winter climate of the MB, the spatial biases over the entire period are presented for key variables of the climate system: gph at 1,000 and $500 \mathrm{hPa}, 850-\mathrm{hPa}$ temperature, and precipitation (Fig. 2). In the Ctrl simulation the gph at both levels is significantly increased over most of the MB (Fig. 2a,b). The strongest deviations are found over the Western Mediterranean (WM), in particular Spain, which is part of the Azores high system. Thus the model seems to overestimate the Azores high and therefore the west-east gradient over the MB in winter. This means that the atmospheric circulation is too zonal compared with ERA40, a well-known bias of all IPCC models (IPCC 2001). The 850-hPa temperature shows smaller deviations, with colder conditions over the Western Sahara and warmer conditions over Russia (Fig. 2c). As $850-\mathrm{hPa}$ temperature is connected to the layer thickness (difference between 500 and $1,000-\mathrm{hPa}$ gph) it is obvious that only a part of the biases in the gph could be explained by changes in $850-\mathrm{hPa}$ temperature. The increase of $850-\mathrm{hPa}$ temperature over Russia is mainly due to stronger advection of warm air masses in the Ctrl simulation than in ERA40. Thus this temperature change is directly related to the fact that the atmospheric circulation is too zonal. However, The biases of gph and temperature are in a similar range as in other model simulations (IPCC 2001). Precipitation is one of the most difficult variables; even reanalysis data sets like ERA40 are not fully reliable in precipitation. Still we compared the mean winter precipitation of the Ctrl simulation with ERA40. The Ctrl simulation overestimates the precipitation over Central Europe and the northern coastline of the MB with respect to the ERA40. In particular over mountain areas, e.g., the Alps, the Ctrl simulation shows enhanced precipitation. This could be traced back to the stronger advection of precipitation by the atmospheric circulation in the Ctrl simulation. Overall, the model seems to overestimate the precipitation over the northern coast of the MB whereas over the sea there are almost no significant changes. Note that the Ctrl simulation shows a similar precipitation pattern as regional modelling results (Lionello and Giorgi 2007).

\subsection{Regional extremes in gph and temperature}

Besides mean behavior, the model should be able to realistically simulate extremes. We focus on minima and maxima of gph and temperature over areas which are relevant for synoptic features of the MB. Therefore, we select the minimum and/or maximum value of the 00 UTC results over the three regions, indicated as red boxes in Fig. 1 (using other times or daily means does not change the results). The result is that we have 90 minimum/maximum values per season; thus the distributions in Figs. 3 and 4 consist of 1,800 values. The maximum $500-\mathrm{hPa}$ gph over Central Europe (CE) is used as an indicator of high pressure events. The minimum of 500 and 1,000-hPa gph of the WM and EM are used as a simple representation of the Genoa and Cyprus lows, respectively. The minimum 850$\mathrm{hPa}$ temperature is used to represent cold intrusions over the WM and EM. For all of these areas and variables we estimate distributions and the related characteristics, like, mean, skewness, excess kurtosis, median, 90th percentile (for maxima), and 10th percentile (for minima). Moreover, the correlation between these variables is used to exhibit possible teleconnections.

The distributions of the maximum 500-hPa gph over CE are presented in Fig. 3. The agreement between ERA40 and the Ctrl simulation is rather good. Compared with Fig. 2 the bias of $25 \mathrm{gpm}$ of the maxima is of similar range as for the seasonal mean. The Stdd is slightly larger in the Ctrl simulation than in ERA40. Despite these rather small differences the shape of the distribution is well simulated, as the skewness and the excess kurtosis agree reasonably well. Note that these two parameters are very sensitive to outliers (Wilks 2006), so we restrict our interpretation to strong changes in these parameters. The time behavior of 
(a)

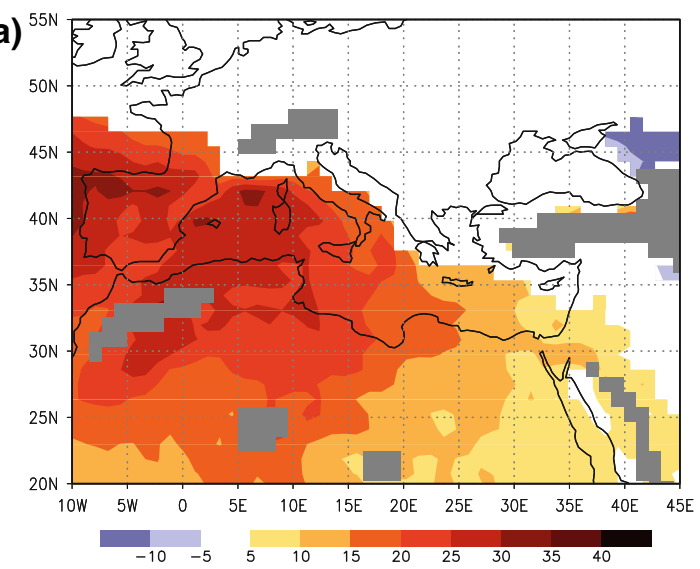

(c)

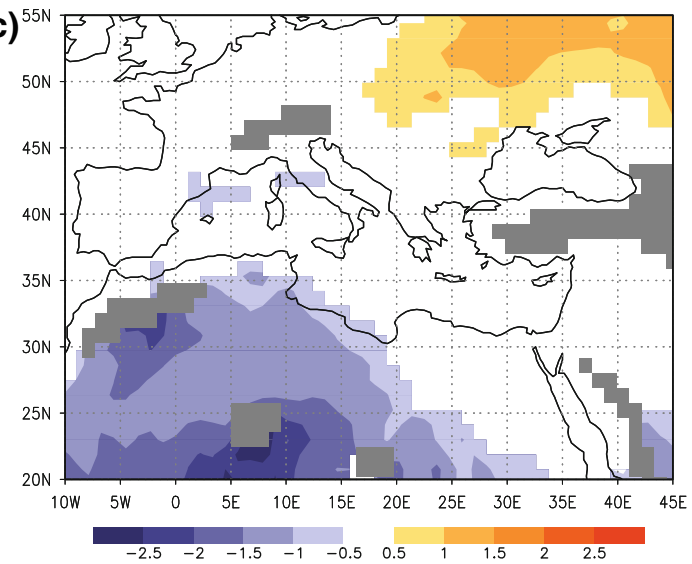

Fig. 2 Winter (DJF) mean difference between the Ctrl simulation and ERA40 for the period 1961-1990 (Ctrl - ERA40): a 1,000-hPa gph (in gpm), b 500-hPa gph (in gpm), c 850-hPa temperature (in K), (b)

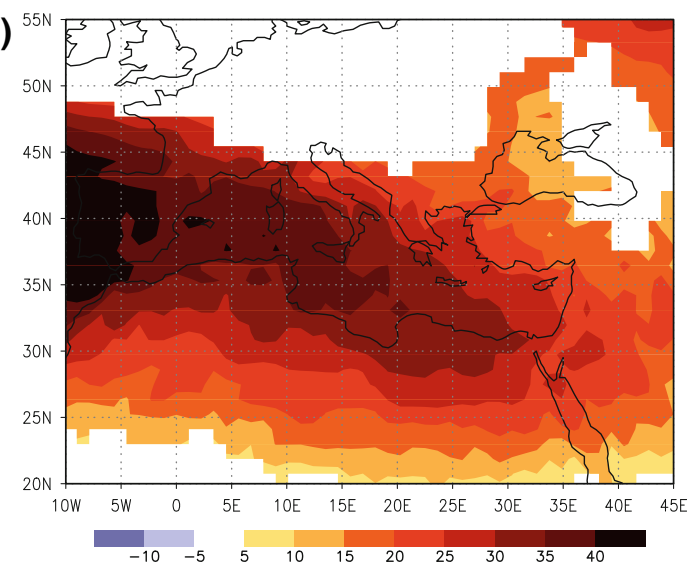

(d) $)^{5}$

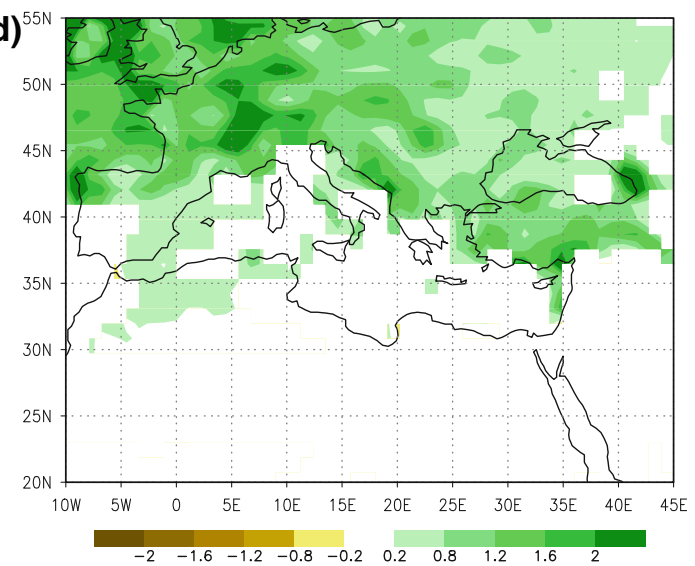

and $\mathbf{d}$ precipitation (in $\mathrm{mm} /$ day). Shading indicates the significance at the 5\% level. Grey shaded areas (higher than 1,000 m) are excluded in $(\mathbf{a}, \mathbf{c})$
Fig. 3 Distributions of maximum 500-hPa gph over CE (bin width $50 \mathrm{gpm}$ ).

Additionally, the mean, the standard deviation $(S t d d)$, the skewness (Skew), the excess kurtosis (Kurt), the median $(M e d)$ and the 90 th percentile (90per) of the distribution are given

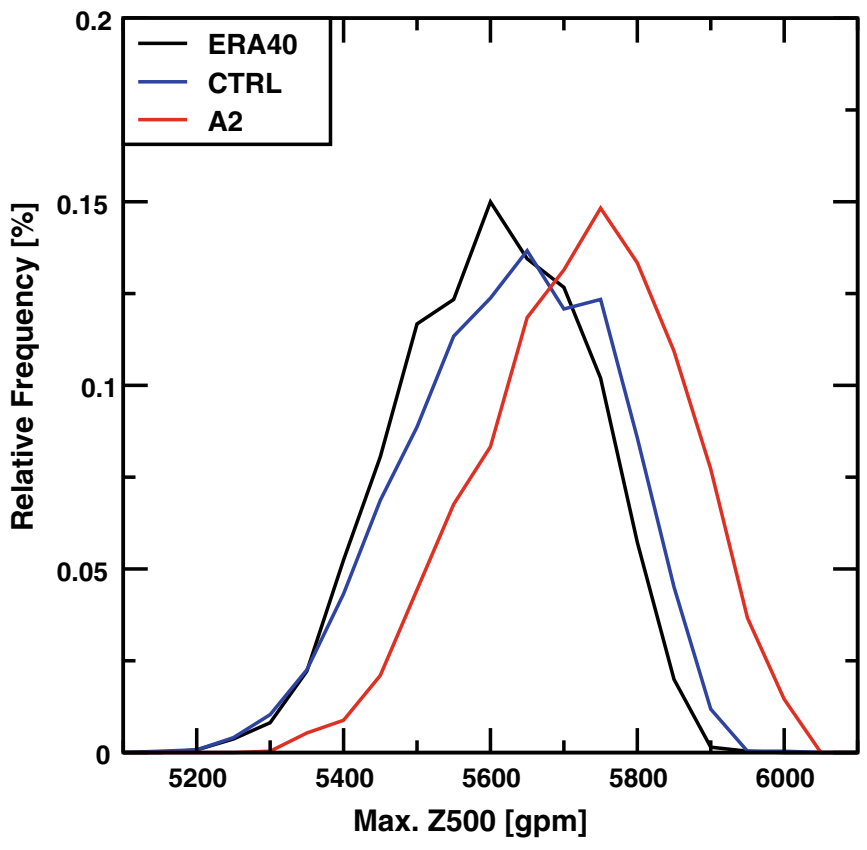

$\begin{array}{llll}\text { Mean: } & 5576 & 5601 & 5698 \\ \text { Stdd: } & 125 & 136 & 131 \\ \text { Skew: } & -0.2 & -0.3 & -0.28 \\ \text { Kurt: } & -0.49 & -0.43 & -0.38 \\ \text { Med: } & 5581 & 5610 & 5707 \\ \text { 90per: } 5737 & 5773 & 5862\end{array}$ 

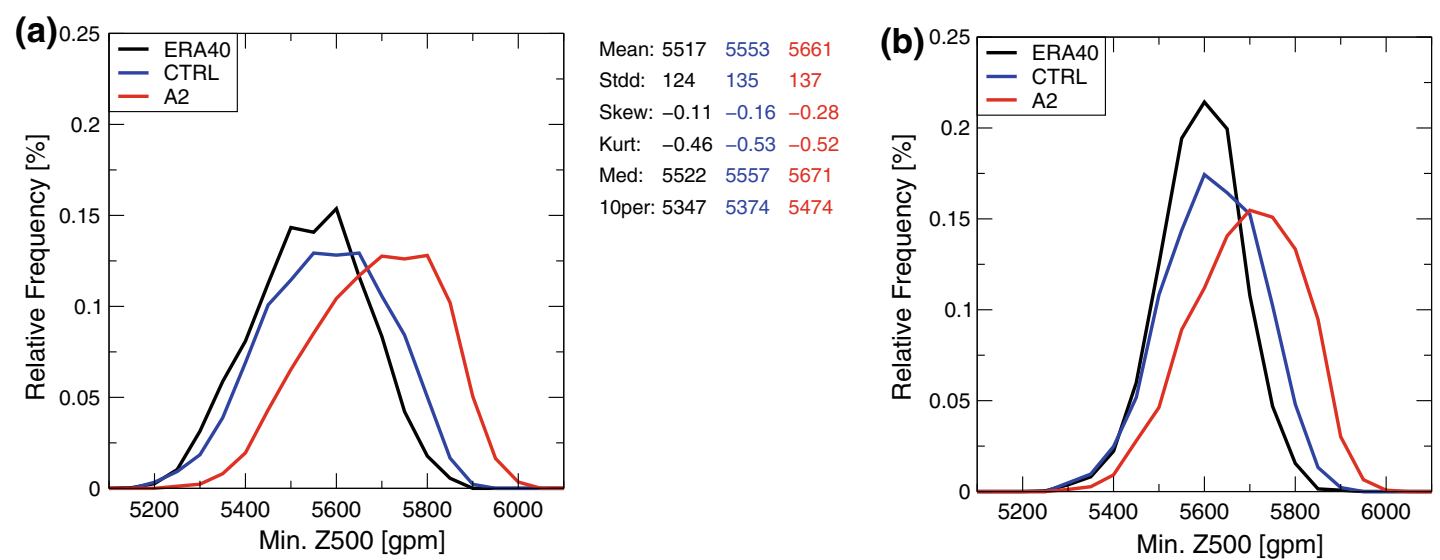

Mean: 556755925665 Stdd: 89106117 Skew: $-0.17-0.19-0.31$ $\begin{array}{llll}\text { Kurt: } & 0.08 & -0.27 & -0.37\end{array}$ Med: 557155945671 10per: 545354545507
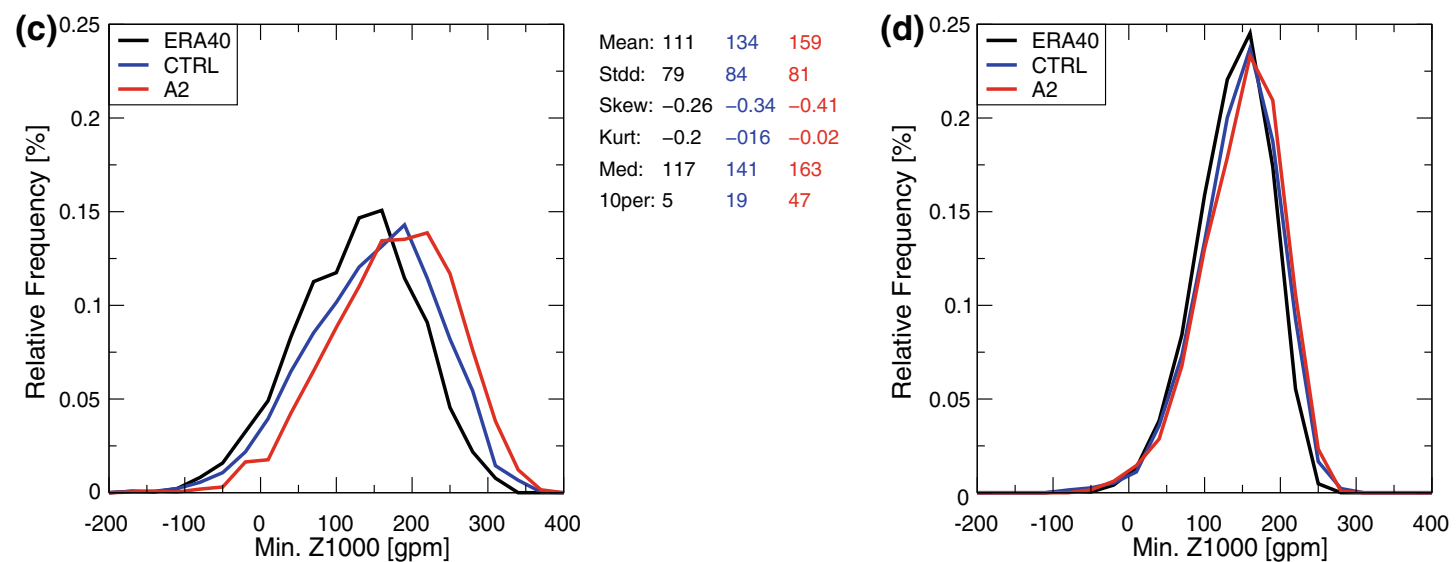

Mean: $123 \quad 129 \quad 133$ Stdd: $48 \quad 52 \quad 53$ Skew: $-0.52-0.6 \quad-0.6$ $\begin{array}{llll}\text { Kurt: } & 0.16 & 0.64 & 0.3\end{array}$ Med: $127 \quad 135 \quad 134$ 10per: $59 \quad 62 \quad 64$
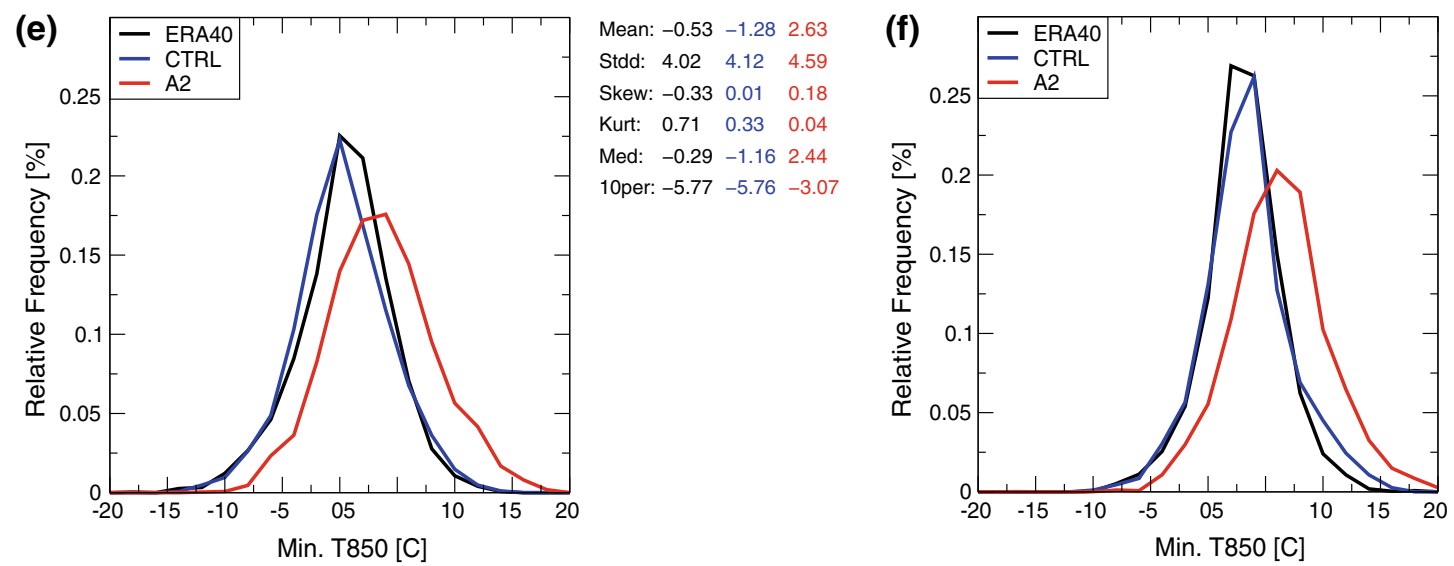

Mean: $2.08 \quad 2.42 \quad 5.25$ Stdd: $\quad 3.31 \quad 3.77 \quad 4.18$ Skew: $-0.12 \quad 0.19 \quad 0.19$ $\begin{array}{llll}\text { Kurt: } & 1.12 & 0.75 & 0.4\end{array}$ Med: $\begin{array}{lll}2.09 & 2.24 \quad 5.22\end{array}$ 10per: $-1.87-2.02 \quad 0.03$

Fig. 4 As Fig. 3, but for (a, c, e) the WM and (b, d, f) EM: a, b the minimum 500-hPa gph (bin width 50 gpm), c, d the minimum 1,000-hPa gph (bin width $30 \mathrm{gpm}$ ) and $\mathbf{e}, \mathbf{f}$ the minimum 850 -hPa temperature (bin width $2^{\circ} \mathrm{C}$ )

maximum 500-hPa gph over $\mathrm{CE}$ is investigated by the times series of maximum $500-\mathrm{hPa}$ gph over $\mathrm{CE}$ (not shown), exceeding 5,750 gpm (resembling the upper $3 \%$ of cases). The Ctrl simulation and ERA40 show a high interannual variability in the occurrence of such events. Additionally, the events cluster in time, suggesting that the model is able to simulate persistent high pressure events over CE.
The mean gph minima over the WM show differences that vary between $36 \mathrm{gpm}$ at the $500-\mathrm{hPa}$ and $23 \mathrm{gpm}$ at the 1,000-hPa level (Figs. 4a, c). For the EM these differences are smaller and insignificant (Figs. $4 \mathrm{~b}, \mathrm{~d}$ ). The Stdds of the 500-hPa gph minima over the WM and EM are slightly larger (nearly significant at the 5\% level), whereas at 1,000 $\mathrm{hPa}$ they are not significant. Moreover, the skewness and the excess kurtosis of the Ctrl simulation resemble the 
values of ERA40 for minima of 1,000 and 500-hPa gph over the WM and EM.

The ability of the model in simulating the distribution of the minimum $850-\mathrm{hPa}$ temperature over the WM and EM is illustrated in Figs. 4e, f. The distributions of the Ctrl simulation agree with ERA40, except for the skewness of the distributions, with a positive simulated skewness versus an observed negative skewness. This means that the model slightly underestimates the population of extreme negative temperature minima with respect to the mean. The analysis of the temporal behavior of the lowest $3 \%$ of the $850-\mathrm{hPa}$ temperature (not shown) in the WM reveals similar characteristics as for the maximum 500-hPa gph over CE: (1) to appear in specific years but not in other and (2), when the minima occur, to persist in consecutive days. This implies that the model captures the high inter-annual variability in the occurrence of extreme events and their tendency to persist. In the EM, such cold intrusion events are strongly related to cyclogenesis (Alpert and Reisin 1986). To investigate this mechanism we applied a composite analysis to the daily 1,000 and 500-hPa gph field using the minimum $850-\mathrm{hPa}$ temperature over the EM as index (not shown). The composite shows that cold events of the 850hPa level are connected with upper-level troughs over the Black Sea and the EM, and with low-level low pressure systems over the EM. This link is found in both the Ctrl simulation and ERA40.

Besides the mean and distribution characteristics, the model should be able to simulate 'regional teleconnections'. The teleconnection patterns found in the Mediterranean are to some extent connected with well known large-scale teleconnections, e.g., the North Atlantic Oscillation. Nevertheless, assessing the spatial coherence between different areas within the Mediterranean is useful to evaluate the Ctrl simulation with ERA40 data. To estimate such 'regional teleconnections' we correlate seasonal means of representative variables in the two tele-connected regions as suggested by Jacobeit et al. (2003) and Ziv et al. (2006). Several large-scale patterns are identified over the $\mathrm{MB}$ and Europe. One of these teleconnection patterns has centers of action over CE and the EM. It is expressed by a seesaw relation, implying a negative correlation between the 30 seasonal averages of the maximum 500-hPa gph in $\mathrm{CE}$ and the minimum 500-hPa gph in the EM. The correlation is -0.23 for ERA40 (significant at the $10 \%$ level) and -0.48 for the Ctrl simulation (significant at the $5 \%$ level). Thus, the model overestimates the connection between $\mathrm{CE}$ and the EM in the Ctrl simulation. Another connection is found between the $850-\mathrm{hPa}$ minimum temperature over the EM and the maximum 500-hPa gph over the WM. Generally speaking, positive anomalies in the gph over the WM enhance the northerly flow over Eastern Europe and transport cold air toward the EM, and vice versa. The correlation is negative and significant in both, -0.71 for ERA40 and -0.66 for the Ctrl simulation. Moreover, the minimum $1,000-\mathrm{hPa}$ gph over the WM is connected with the one over the EM, which is indicated by positive correlations of +0.64 for the observations and +0.44 for the Ctrl simulation (all significant at the $5 \%$ level).

The differences between the Ctrl simulation and ERA40 in capturing the distributions of extremes and their characteristics are minor and in most cases not significant. Thus, the model is able to realistically reproduce gph and temperature extremes over key areas of the MB, as well as synoptic to large-scale relations over the MB.

\subsection{Cyclone characteristics}

The previous subsection focuses on the winter synoptic features of the MB, using representative indices to characterize them. Here, we investigate how the model is able to reproduce cyclone characteristics. Therefore, cyclones are individually detected and tracked to estimate the cyclone center density (cyclone center occurrences per total number of observation time steps and area of $\left.(1,000 \mathrm{~km})^{2}\right)$, the number of cyclones, cyclone occurrences (number of time steps when a cyclone is detected in the specified area), and their intensity. The intensity is estimated by the geostrophically adjusted 1,000-hPa gph gradient (reference latitude of $60^{\circ} \mathrm{N}$ ) within a radius of $1,000 \mathrm{~km}$ around the cyclone center (Raible 2007; Raible et al. 2008).

The spatial distribution of cyclones traveling along the $\mathrm{MB}$ is illustrated by the cyclone center density (Fig. 5). The main maxima over the Gulf of Genoa, Adriatic, Ionian and Aegean Seas and Cyprus are simulated. However, these maxima are slightly underestimated by the Ctrl simulation of ECHAM5. The extended maxima ranging from the Gulf of Lyon along the Italian coast to Sardinia is underestimated, in particular over the Gulf of Genoa. A similar behavior is found for the Adriatic and the Ionian Seas. Besides the fact that the slightly coarser resolution of ECHAM5 plays a role in these deviations, the model shows a clear mean bias to higher 1,000-hPa gph over the western to central part of the Mediterranean (Fig. 2a). The maxima in the distribution of cyclones over the Aegean Sea and Cyprus are better reproduced by the Ctrl simulation.

Another striking difference is that the pattern of cyclone center density of the Ctrl simulation shows stronger maxima over the Sahara and the Middle East than in ERA40. This difference is strongly related to an overestimation of heat lows of the Ctrl simulation. Heat lows develop due to intensive heating of the surface. Thus, they are mainly found over continental areas particularly over the subtropics. They are typically weak and stationary. To test if 

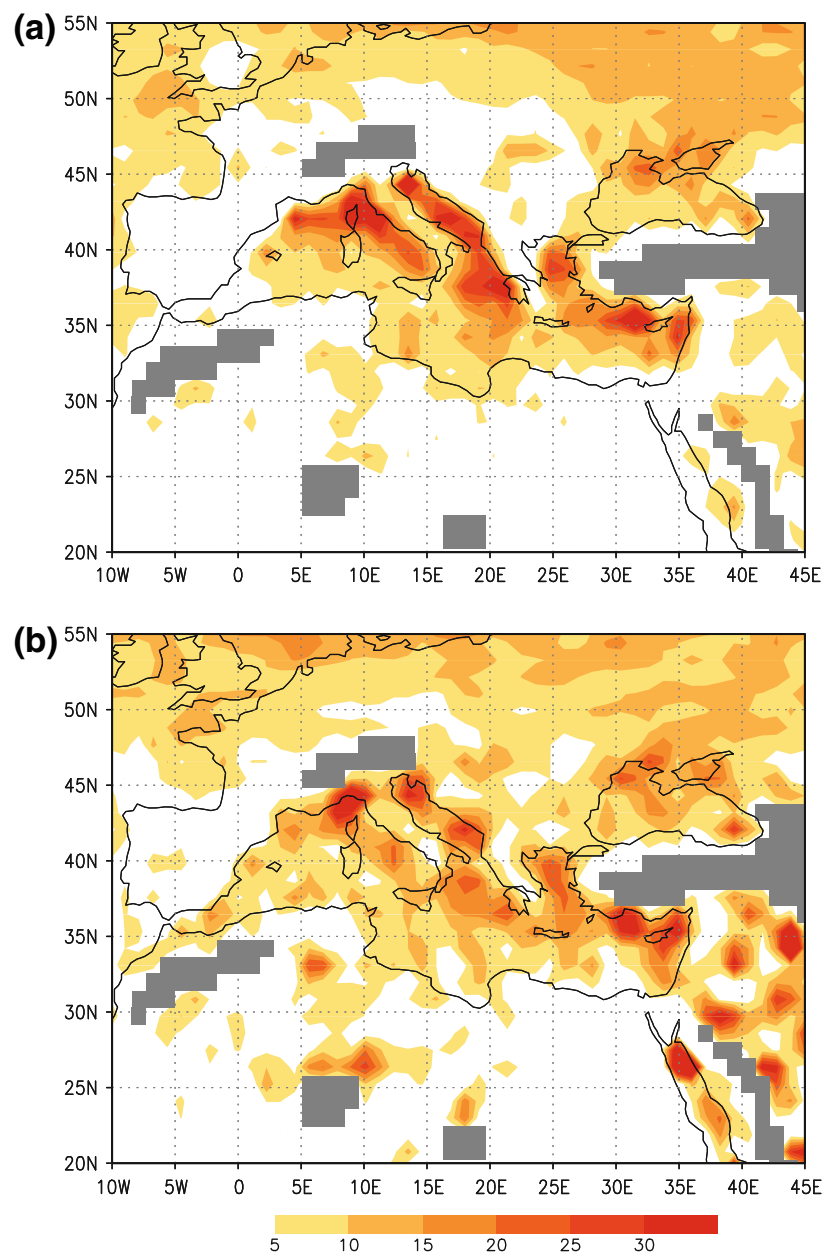

Fig. 5 Mean cyclone center density (contour interval: 5 cyclones per $\left.(1,000 \mathrm{~km})^{2}\right)$ in winter (DJF) for a ERA40 and b the Ctrl simulation for the period 1961-1990. Grey shaded areas (higher than 1,000 m) are excluded in the cyclone detection and tracking method

low pressure systems over the southern and eastern parts of the domain are heat lows, we first investigated case studies focusing on these regions. The relationship between high temperatures and low pressure systems is clearly found. Second, the cyclone detection and tracking parameters are changed to exclude weak minima or stationary minima. The result was that the maxima of cyclone center density found over the southern and eastern part of the domain are reduced. This indicates that heat lows seem to be overestimated in the Ctrl simulation. Note that for the analysis presented in this study the standard parameters are used, because with a stricter parameter setting the cyclone center density is reduced over other parts of the MB (e.g., Genoa) which are partly stationary cyclones. Another artificial maximum is simulated over the Red Sea in the Ctrl simulation, which is probably due to the surrounding positive mean biases in 1,000-hPa gph fields of the Ctrl simulation shown in Fig. 2a. Nevertheless, the comparison of the Ctrl simulation with ERA40 shows an overall good agreement with respect to the pattern and the maxima of cyclone center density over the MB.

To give an overview, we show the mean cyclone characteristics for the WM and EM, separately (Table 1). Note that the areas (see the blue shaded boxes in Fig. 1) for which the cyclone characteristics are referred are larger than those used for showing regional extremes of Sect. 3.2. In the WM the simulated number of cyclones and cyclones' occurrence are in agreement with ERA40. The intensity of extreme WM cyclones is slightly overestimated by the Ctrl simulation (5\%). In the EM the deviations between ERA40 and the Ctrl simulations are higher than in the WM, showing more cyclones in the Ctrl simulation than in ERA40. As for the WM, the simulated extreme intensity is increased by $5 \%$. Still, the deviations in the mean characteristics and in the pattern of cyclone center density are minor, so we conclude that the model is able to realistically simulate cyclones and their characteristics over the MB.

\section{Future climate projection: A2 scenario for 2071-2100}

This section presents results of the model simulation for 2071-2100, based on the A2 scenario simulation. The future scenario is compared with the Ctrl simulation (1961-1990).

\subsection{Mean fields of temperature and gph}

For the last 3 decades of the twenty-first century the A2 scenario shows a general warming throughout the troposphere in winter (Fig. 6). In lower-levels (850 hPa, Fig. 6a), the temperature rise varies between roughly $2-4^{\circ} \mathrm{C}$. The spatial distribution of the temperature change shows a pronounced maximum of $4.2^{\circ} \mathrm{C}$ over Morocco, two minima over the Black Sea and over the EM $(+2.6$ and $\left.+2.9^{\circ} \mathrm{C}\right)$, and the most pronounced minimum $\left(+2.0^{\circ} \mathrm{C}\right)$ over southern Egypt. The south to north gradient over WM is increased as well as the west to east gradient. At midlevels $(500 \mathrm{hPa}$, Fig. 6b), the temperature increases by roughly 3.5 to $5.2^{\circ} \mathrm{C}$. The maximum is again located over the Morocco inducing an increase of the south to north gradient over Western Europe. In addition, a 'tongue' of relatively low temperatures extends from Ukraine toward the Red-Sea leading to an increased west to east gradient similar to $850-\mathrm{hPa}$ level.

For the 1,000-hPa gph, we find a decrease from $180 \mathrm{gpm}$ over the WM to $150 \mathrm{gpm}$ over the EM in Ctrl simulation (Fig. 7a). This gradient is increased in the $\mathrm{A} 2$ simulation as reflected by the rise in the gph over the WM to $210 \mathrm{gpm}$, while no change is noted over the EM (Fig. 7b). The difference in 1,000-hPa gph between the A2 and the Ctrl simulation shows an increase in gph all over the MB, with 
Table 1 Winter cyclone characteristics of the MB in ERA40, the Ctrl, and the A2 simulation

\begin{tabular}{|c|c|c|c|c|c|c|}
\hline \multirow[t]{2}{*}{ Variable } & \multicolumn{3}{|l|}{ WM } & \multicolumn{3}{|l|}{ EM } \\
\hline & ERA40 & Ctrl & $\mathrm{A} 2$ & ERA40 & Ctrl & $\mathrm{A} 2$ \\
\hline Number of cyclones & 16.7 & 16.7 & 15.0 & 11.4 & 13.8 & 14.2 \\
\hline Cyclone occurrences (days) & 61.5 & 61.2 & 55.4 & 44.4 & 51.8 & 51.5 \\
\hline Upper 10th gradient intensity $(\mathrm{m} / 1,000 \mathrm{~km})$ & 162 & 169 & 164 & 163 & 174 & 166 \\
\hline
\end{tabular}

(a)

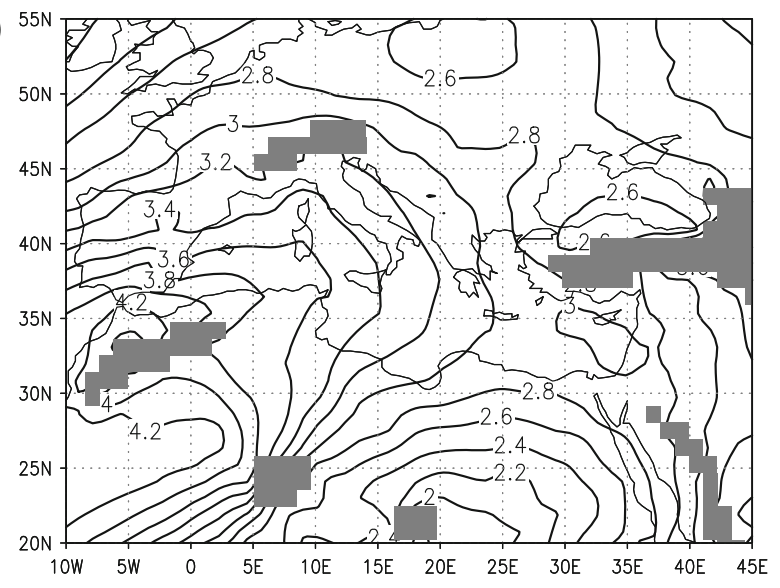

(b)

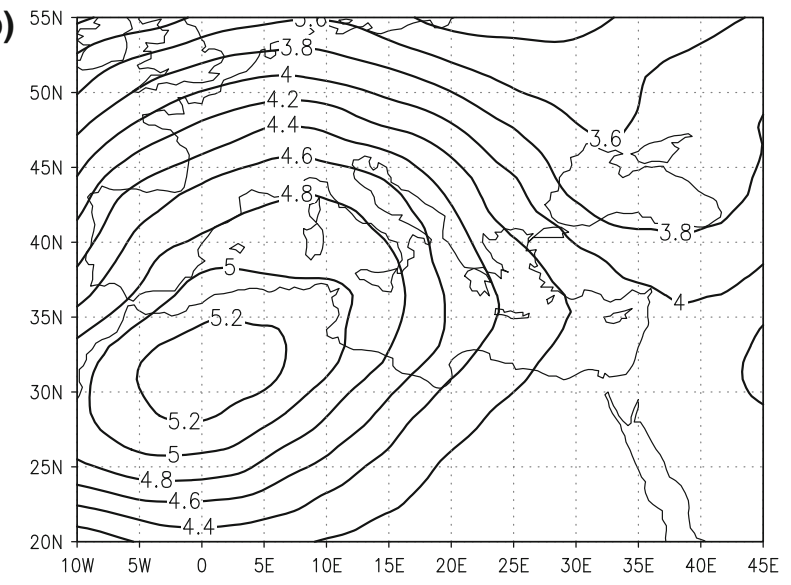

Fig. 6 Winter (DJF) mean temperature difference (contour interval: $0.2^{\circ} \mathrm{C}$ ) between A2 (2071-2100) and the Ctrl simulation (1961-1990) at a $850 \mathrm{hPa}$ and b $500 \mathrm{hPa}$. All changes displayed are at least significant at a level of 5\%. Grey shaded areas (higher than 1,000 m) are excluded in (a)

a maximum of more than $100 \mathrm{gpm}$ over the WM (not shown).

For the 500-hPa gph, the trough over the MB changes its location and orientation considerably, comparing the Ctrl and the A2 simulations (Figs. 7c,d). While in the Ctrl the trough is located over the WM, oriented northeast-southwest, it shifts to the EM and changes its orientation to north-south in the A2 simulation. The difference in 500$\mathrm{hPa}$ gph between the simulations exhibits an increase of 70-105 gpm over the WM (not shown).
The increase in temperature and the changes of the gph are linked, as the layer thickness between the 1,000 and 500-hPa levels is an estimate of the temperature. Comparing the patterns, the increase of $500-\mathrm{hPa}$ gph over the WM is clearly related to a stronger temperature increase over this region. Thus, the shift of the trough and the change of its orientation are partly driven by temperature.

\subsection{Regional extremes in gph and temperature}

To assess changes in extremes of synoptic-scale features we investigate the distributions of variables in key regions as introduced in Sect. 3.2 and shown in Figs. 3 and 4.

The distribution of the maximum 500-hPa gph is shifted to higher mean gphs in the A2 simulation (Fig. 3). However, there is no significant change in the Stdd, the skewness, and the excess kurtosis. Thus, the shape of the distribution of the A2 simulation is similar to the one of the Ctrl simulation, suggesting that extremes of high pressure in $\mathrm{CE}$ are similar in the $\mathrm{A} 2$ simulation.

For the distributions of the minimum 1,000 and 500-hPa gph over the WM, similar mean changes are found as for the maximum over CE (Figs. 4a, c). The shape of the distribution is again not altered, suggesting no change in extremes. For the $850-\mathrm{hPa}$ minimum temperature a clear mean shift towards warmer conditions is simulated in the A2 simulation (Fig. 4e). This warming explains the difference in increase between the 500 and 1,000-hPa gph. In contrast to the behavior of the 500 and 1,000-hPa gph over the WM the temperature also shows an increase in the Stdd, which seems to have no implication on the gph fields. Thus, cold intrusions seems to be less relevant in the WM.

The EM behaves differently. The minimum 500-hPa gph representing the upper-level trough shows an increase of the mean, but also a significant increase of the Stdd by $10 \%$ (Fig. 4b). This increase in the Stdd implies an increase in extreme trough events. However, the minimum 1,000-hPa gph, which roughly characterize the Cyprus Low, shows no change in the mean or the Stdd (Fig. 4d). The changes in the 500-hPa gph fit the changes of the minimum in the 850$\mathrm{hPa}$ temperature over the EM (Fig. 4f). Moreover, the distribution for the A2 simulation gets wider, as is illustrated by an increase in the Stdd of the 850-hPa temperature. For cold intrusions, the temperature anomaly with 
(a)

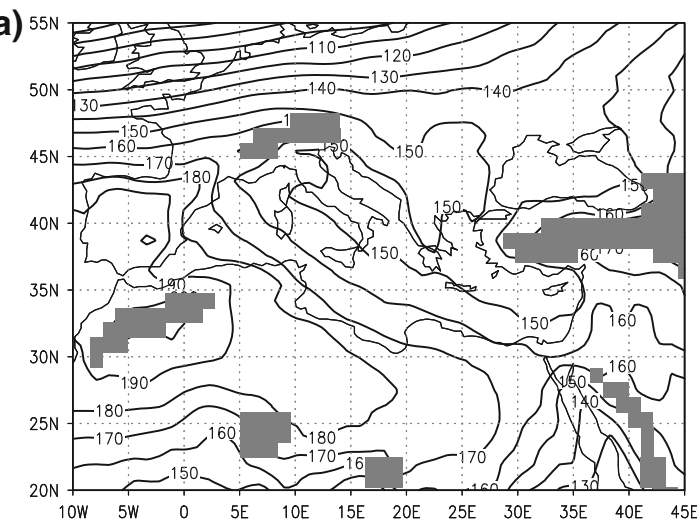

(c)

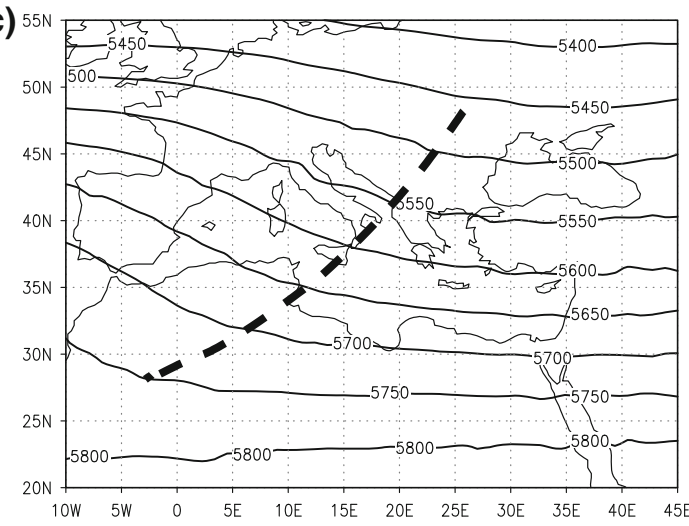

Fig. 7 Mean gph field for a, b the 1,000-hPa (contour interval: 10 gpm) and c, d 500-hPa level (contour interval: $50 \mathrm{gpm}$ ) in winter (DJF). a, c show the Ctrl simulation (1961-1990) and b, d the A2

respect to the background is the key factor, and not the mean temperature change. Hence, the change in Stdd suggests that the winter $850-\mathrm{hPa}$ temperatures are expected to become more extreme with respect to the new mean (A2 scenario). Thus, there is an apparent contradiction, as an increase of cold intrusion implies more cyclogenesis (see Sect. 3.2) and therefore a change in the distribution of minimum 1000-hPa gph. In the following sections we cope with this superficial contradiction.

The 'regional teleconnections' described in Sect. 3.2 show a decrease of the correlations to insignificant values, but the signs of the correlation remain. The connection of the minimum 1,000-hPa gph over the WM and the EM is still significant with a positive correlation coefficient of +0.33 , but lower than in ERA40 or the Ctrl simulation. Note that it is difficult to estimate changes of the correlation matrix in small samples of $30 \mathrm{yrs}$. Nevertheless, the changes of the teleconnections hint to a different behavior of the WM and EM, as indicated previously.

\subsection{Cyclone characteristics}

The classical way to characterize cyclone variability is the storm track (Blackmon 1976), illustrated by the 2.5-6.5 (b)

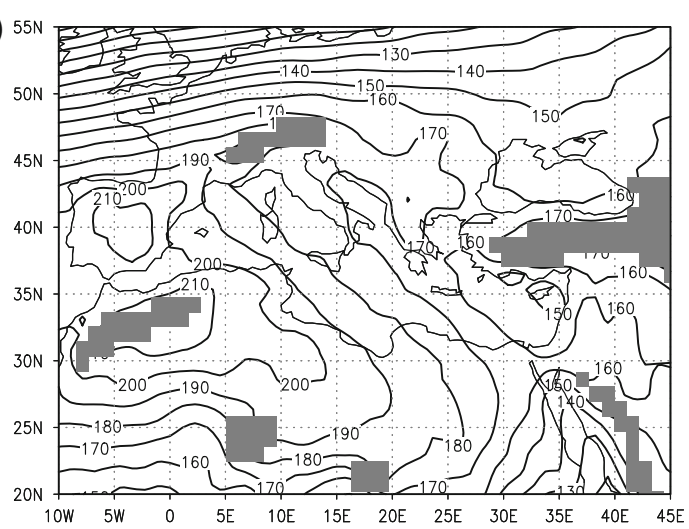

(d)

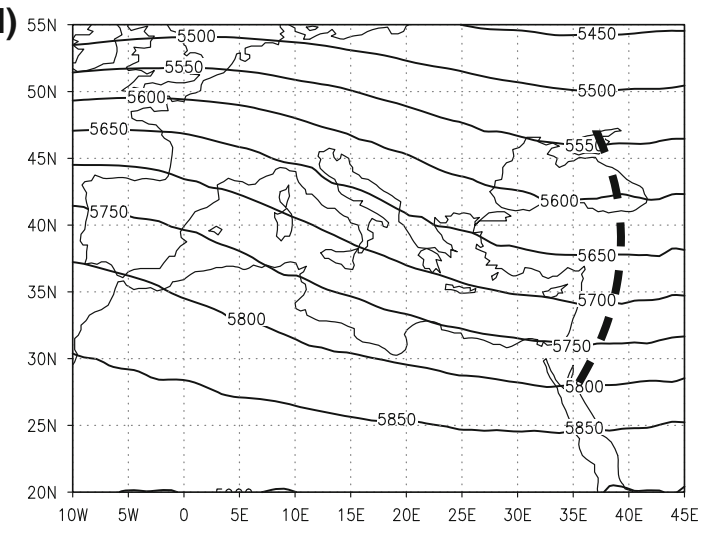

scenario simulation (2071-2100). The main troughs are denoted by dashed thick line in the lower panels. Grey shaded areas (higher than $1,000 \mathrm{~m}$ ) are excluded in $\mathbf{a}, \mathbf{b}$

days bandpass filtered gph field (Fig. 8a). Comparing the A2 with the Ctrl simulation, the 2.5-6.5 days bandpass filtered gph field shows a significant decrease over western North Africa and, less significant, over the WM, whereas a significant increase is simulated over Eastern Europe with a maximum over the Crimea/Ukraine. Both changes are found in the Lagrangian measure of the cyclone center density (Fig. 8b). Additionally, a clear decrease of cyclone tracks is found in the western and central part of the MB, whereas in the area of the Cyprus Low a slight increase is found (not significant at the 5\% level). These changes are not well reflected in the classical storm track, as surface cyclones are not necessarily a mirror for transient behavior in the mid-troposphere. This is particularly true in the Mediterranean, where many transients are shallow low pressure systems. Thus, to gain comprehensive insights of the transients of the Mediterranean both measures have to be investigated.

To assess the cyclone characteristics in more detail the number of cyclones, cyclone occurrences, and extreme intensity (10th percentile) are calculated and presented in Table 1 for the WM and EM (blue shaded areas in Fig. 1). Comparing the A2 with the Ctrl simulation we find that in the WM the number of cyclones and the occurrence of 
(a)

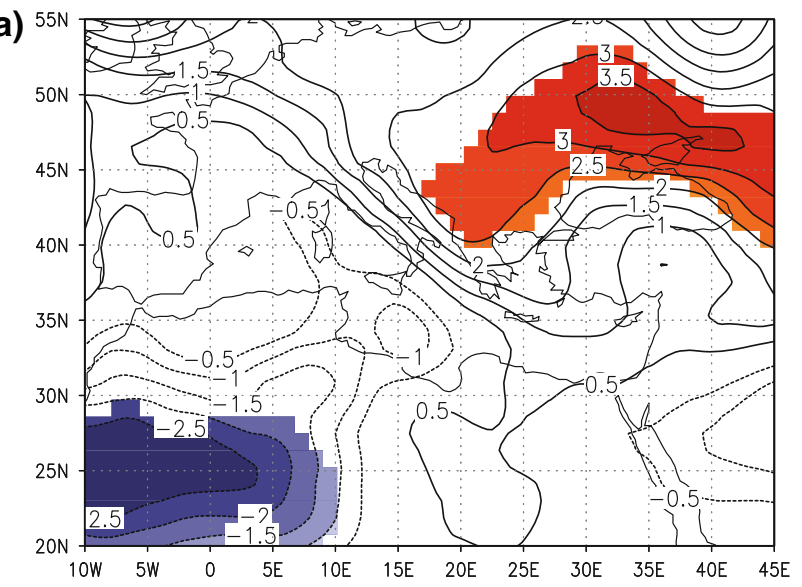

(b)

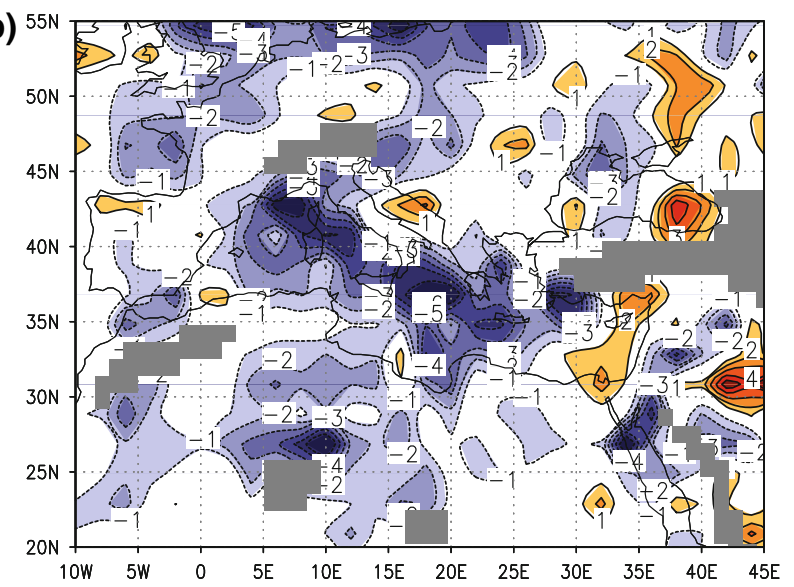

Fig. 8 Mean difference between the A2 scenario (2071-2100) and the Ctrl simulation (1961-1990) in winter (DJF): a 2.5-6.5 days bandpass filtered standard deviation of the 500-hPa gph (contour interval: $0.5 \mathrm{gpm}$; $5 \%$ significance level is shaded). b Cyclone center density (contour interval: 1 cyclone per $\left(1,000 \mathrm{~km}^{2}\right)$. Note that a significance test is not applied to $\mathbf{b}$, because one has to strongly smooth the fields and in one season the population in the MB is small, but the differences are in the range of up to $30 \%$ and at least in the WM large enough to be significant. Grey shaded areas (higher than $1,000 \mathrm{~m}$ ) are excluded in $\mathbf{b}$

cyclones decrease by $\sim 10 \%$ (significant at a level of 5\%), respectively. The extreme intensity shows an insignificant decrease of approximately 3\%. For EM cyclones, no statistically significant change is found in the number or occurrences, but a $\sim 5 \%$ decrease is found in their extreme intensity (almost significant at a level of 5\%). This result is consistent with the mean cyclone center density in the EM (Fig. 8b) and the absence of a significant difference in the mean minimum 1,000-hPa gph (Fig. 4d).

\subsection{Dynamical aspects}

To better understand these changes in cyclone characteristics a set of relevant dynamic quantities (described in Sect. 2) is investigated in more detail for the A2 scenario.
To show also effects of upstream processes, the domain is augmented to $60^{\circ} \mathrm{W}-45^{\circ} \mathrm{E}, 20^{\circ} \mathrm{N}-70^{\circ} \mathrm{N}$.

The baroclinic potential for cyclogenesis is estimated by the maximum Eady growth rate (Eady 1949) for the Ctrl and the A2 simulations in two layers: 700-500 and 500-300 hPa (Figs. 9a, b). The general spatial pattern of the Ctrl simulation (not shown) exhibits two maxima, the major one over the North Atlantic, extending to the British Islands, and the other in the South-Eastern (Mesopotamia) part of the domain. The difference between the two simulations (Figs. 9a, b) indicates that no significant change is expected to take place over the MB and Europe. One exception is Spain, which shows a significant decrease of baroclinicity at the layer 500-300 $\mathrm{hPa}$. The major changes are found over North Africa and the North Atlantic in both layers. The baroclinicity is substantially decreased by up to $\sim 20 \%$. The comparison of this with the change in mean temperature (Fig. 6) suggests an increase in baroclinicity as the horizontal temperature gradient slightly increases. However, the maximum Eady growth rate depends on two factor: the horizontal temperature gradient and the static stability. Thus, it is necessary to analyze the static stability separately, in order to understand this discrepancy. In Fig. 9c, the difference in static stability between the A2 and the Ctrl simulation in the layer between 700 and $500 \mathrm{hPa}$ is displayed. The static stability significantly increases over the entire region (up to $15 \%$ ). A similar difference is found for the static stability between 500 and $300 \mathrm{hPa}$ (not shown). The maximum Eady growth rate seems to be dominated by the effect of the static stability over the MB in particular over Northern Africa. The reduction of the maximum Eady growth rate due to an increased static stability in this region suggest that the cyclone development over the Sahara (HMSO 1962; Romem et al. 2007) will become less effective. Note that this region is one of the cyclogenesis areas for the MB, in particular for the WM. For the EM, the static stability is significantly increased, which suggests a reduction of cyclones in this region. However, as cold intrusions are more intense in the A2 simulation the reduction of cyclones by increased static stability is compensated by increased cyclogenesis induced by cold intrusions (solving the caveat mentioned above).

Besides stability and baroclinicity, the interaction between eddies and the mean flow is an important process, which could be partly responsible for changes in cyclone characteristics. A suitable measure is the $\mathbf{E}$-vector (Hoskins et al. 1983). The horizontal bandpass filtered $\mathbf{E}_{h}$-vector at $250 \mathrm{hPa}$ (Fig. 10a) shows that in general the energy flux of these transient waves is zonally oriented over the Central Atlantic to Europe, but it is tilted meridionally over the MB. Comparing the A2 with the Ctrl simulation no significant change is evident, except for Western Europe, in 


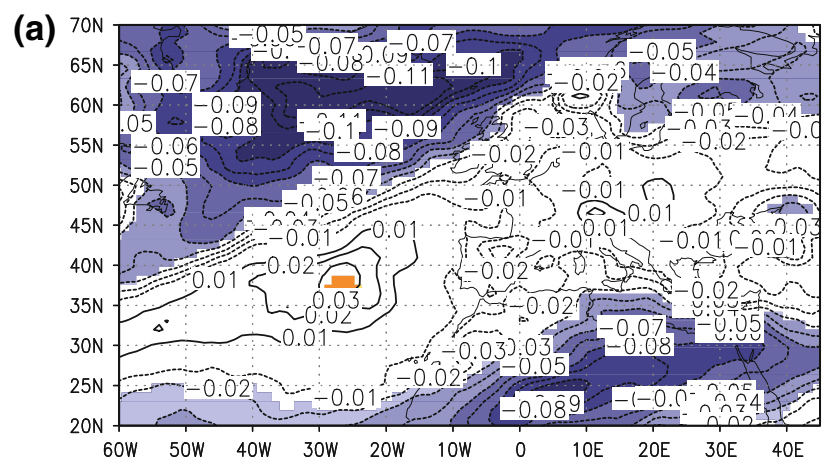

(b)

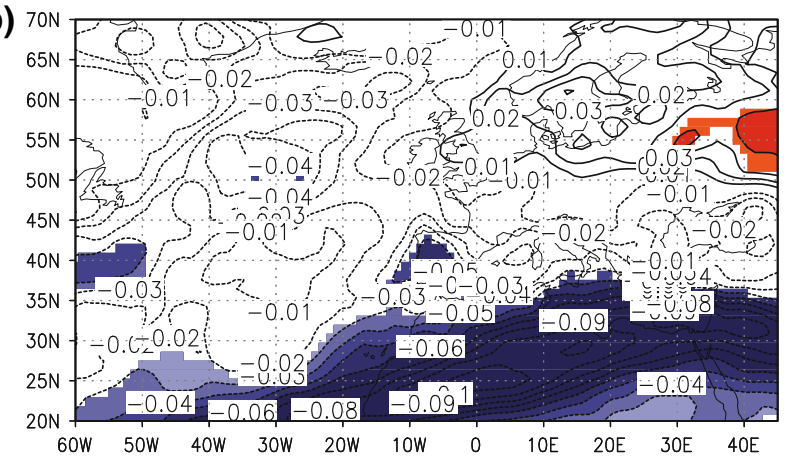

(c)

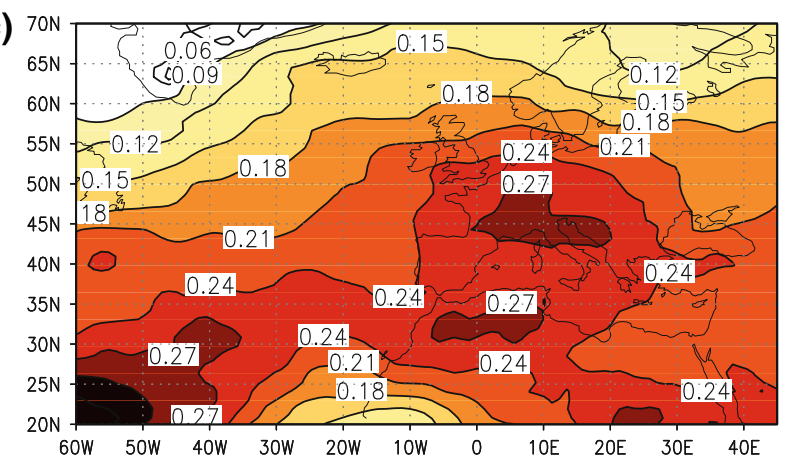

Fig. 9 Baroclinicity and static stability difference between A2 (2071-2100) and Ctrl simulation (1961-1990) in winter (DJF): a Maximum Eady growth rate between 700 and $500 \mathrm{hPa}, \mathbf{b}$ maximum Eady growth rate between 500 and $300 \mathrm{hPa}$, and c static stability between 700 and $500 \mathrm{hPa}$. Contour intervals are $0.01 \mathrm{day}^{-1}$ in $(\mathbf{a}, \mathbf{b})$ and $0.05 \mathrm{~m}^{2} /(\mathrm{K} \mathrm{kg}) \mathrm{K} / \mathrm{Pa}$ in c. Shading indicates the significance level of $5 \%$

which a small anti-clockwise tilt of the vectors is found in the A2 simulation. This means that the eddy kinetic energy flux is more zonally oriented in the WM, i.e., more eddy kinetic energy is transported to CE and less to the area of the Genoa Low. More obvious is the change in local production of eddy-kinetic energy $\mathbf{E}_{h} \cdot \mathbf{D}$. In the Ctrl simulation $\mathbf{E}_{h} \cdot \mathbf{D}$ is negative in the north western part, i.e., eddy kinetic energy is transformed to kinetic energy of the mean flow. Over the MB, the Ctrl simulation shows an area of production of eddy kinetic energy due to the transformation of kinetic energy from the mean flow (positive values of $\mathbf{E}_{h} \cdot \mathbf{D} ;$ Fig. 10c). Both areas are affected in the A2 scenario
(Fig. 10e). $\mathbf{E}_{h} \cdot \mathbf{D}$ significantly decreases over North Africa, which is one area of cyclogenesis for the WM. This perfectly agrees well with results of the classical storm track and the cyclone center density analysis (Fig. 8a). In the $\mathrm{EM}$, no significant change is found, whereas, north of the $\mathrm{EM}$, the area in which eddy kinetic energy is transformed to kinetic energy of the mean flow significantly expands. Again, this is reflected in the storm track and to some extent by a reduction of cyclones over that region (Fig. 8a). Thus, this result indicates that major changes are expected in the WM rather than in the EM. It shows that changes in the energy transformation from the mean flow to transient eddies are important in explaining the decrease in cyclonic activity over the WM.

In addition to the transient wave activity, stationary waves affect the MB. Therefore, the stationary wave flux $\mathbf{F}_{s}$ is investigated (Fig. 10, right column). The horizontal flux of stationary wave energy has a similar structure to the $\mathbf{E}_{h}$-vector in the Ctrl simulation with a more zonal orientation in the north western part and a meridional orientation over CE and the MB (Fig. 10b). Moreover, the horizontal stationary wave flux in the Ctrl simulation is strongly reduced in the EM with respect to the WM (Fig. 10b). Comparing the A2 simulation with the Ctrl simulation the horizontal flux at $250 \mathrm{hPa}$ shows a stronger inflow of stationary wave activity (Fig. 10b). In the WM the vectors are more zonally oriented, whereas the orientation in the EM is unchanged, which is in agreement with the displacement of the upper-trough (Figs. 7c, d). To investigate the convergence or divergence of $\mathbf{F}_{s}$ in the upper troposphere, i.e., the dissipation or production of stationary waves, the vertical component of $\mathbf{F}_{s}$ is shown for the Ctrl simulation (Fig. 10d), together with the difference between the simulations (Fig. 10f). Besides the major maximum over the Atlantic, areas over England, Spain and the Atlas Mountains are important for stationary wave production. In the A2 simulation, the production of stationary waves increases over England to France, whereas a decrease is found over the Atlas Mountains. To investigate the impact of the increased production of stationary waves over England to France we define an index of stationary wave production, i.e., normalized winter means of the area $10^{\circ} \mathrm{W}-5^{\circ} \mathrm{E}$ and $48^{\circ} \mathrm{N}-52^{\circ} \mathrm{N}$. Correlating this index with the $1,000-\mathrm{hPa}$ and the 500-hPa gph exhibits a wave train, where a positive index (increased stationary wave production) is associated with negative gph anomalies over the Central Atlantic and positive anomalies over the Caribbean and CE (not shown). Thus, cyclones of the WM originating from the Atlantic are more often blocked by this wave train in the $\mathrm{A} 2$ simulation at the end of the twenty-first century. In the EM no significant change is found in the A2 simulation, which supports the absence of significant change in synoptic-scale features over that region. 

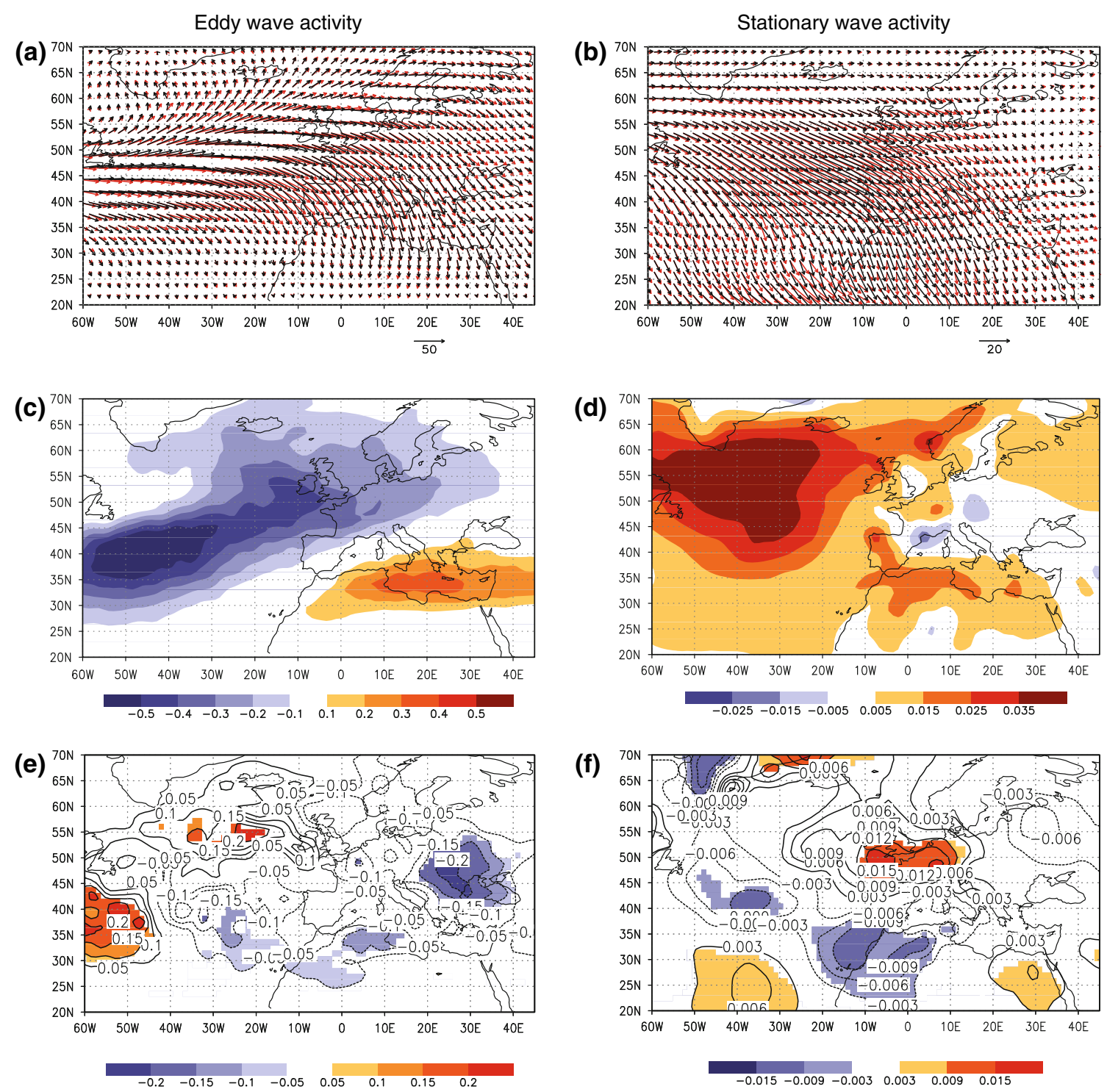

Fig. 10 a, c, e 2.5-6 days bandpass filtered eddy wave activity in winter (DJF): a horizontal $\mathbf{E}_{h}$-vector at $250 \mathrm{hPa}$ (length of the unit vector: $40 \mathrm{~m}^{2} \mathrm{~s}^{-2}$ ) for the Ctrl (1961-1990; black) and the A2 simulation (2071-2100; red), $\mathbf{c}$ barotropic production $\mathbf{E}_{h} \cdot \mathbf{D}$ (contours: $0.1 \times 1,000 \mathrm{~m}^{2} \mathrm{~s}^{-3}$ ) for the Ctrl simulation between 250 and $850 \mathrm{hPa}$ and $\mathbf{e}$ the difference in $\mathbf{E}_{h} \cdot \mathbf{D}$ between the $\mathrm{A} 2$ and the Ctrl simulation (contours: $0.05 \times 1,000 \mathrm{~m}^{2} \mathrm{~s}^{-3}$ ). b, d, f Stationary wave activity flux

\subsection{Precipitation}

Changes in synoptic-scale variations, in particular cyclones, have a significant impact on the hydrological cycle in the MB (Raible 2007), in particular in winter, the most important season for precipitation (HMSO 1962).

To gain insight, winter mean precipitation for the Ctrl simulation is presented in Fig. 11a and the relative change in the A2 simulation is shown in Fig. 11b. The difference between the simulations shows a significant decrease over

(f)

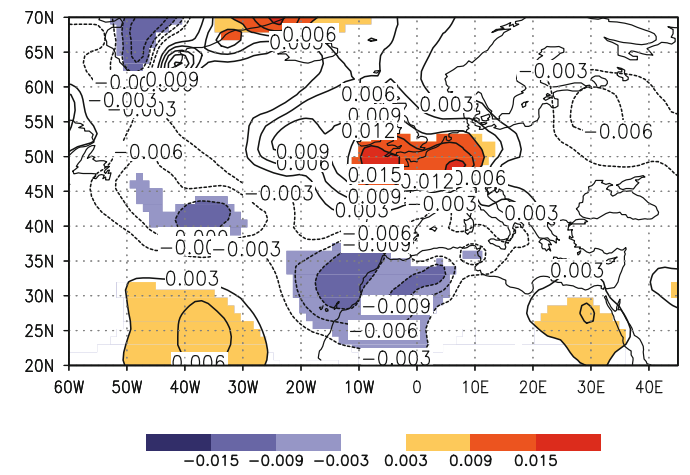

in winter (DJF): $\mathbf{b}$ horizontal $\mathbf{F}_{s}$-vector (length of unit vector: $20 \mathrm{~m}^{2} \mathrm{~s}^{-2}$ ) at $250 \mathrm{hPa}$ for the Ctrl (black) and the A2 simulation (red), $\mathbf{d}$ the vertical component of $\mathbf{F}_{s}$ (contours: $0.005 \mathrm{~m}^{2} \mathrm{~s}^{-2}$ ) in the Ctrl simulation between 250 and $850 \mathrm{hPa}$ and $\mathbf{f}$ the difference of the vertical component of $\mathbf{F}_{s}$ between $\mathrm{A} 2$ and the Ctrl simulation (contours: $0.003 \mathrm{~m}^{2} \mathrm{~s}^{-2}$ ). Significant changes at a level of $5 \%$ are shaded in $\mathbf{e}, \mathbf{f}$

the majority of the MB, except for the EM where no significant change is found. The reduction in precipitation is pronounced along the North African coast of the central and WM (reaching up to 50\%). The decrease in the A2 scenario is directly related to the reduction in the number of cyclones mainly over the WM, as a correlation analysis between the number of WM cyclones and precipitation fields implies (not shown). The lack in precipitation change over the EM agrees with the results that there is no clear change in cyclone activity over this region in the A2 scenario. 
(a)

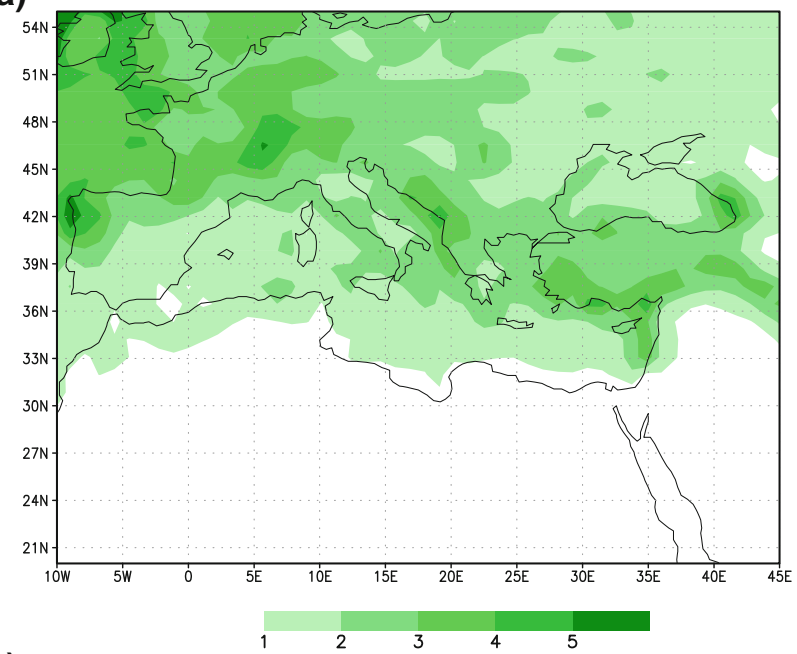

(b)

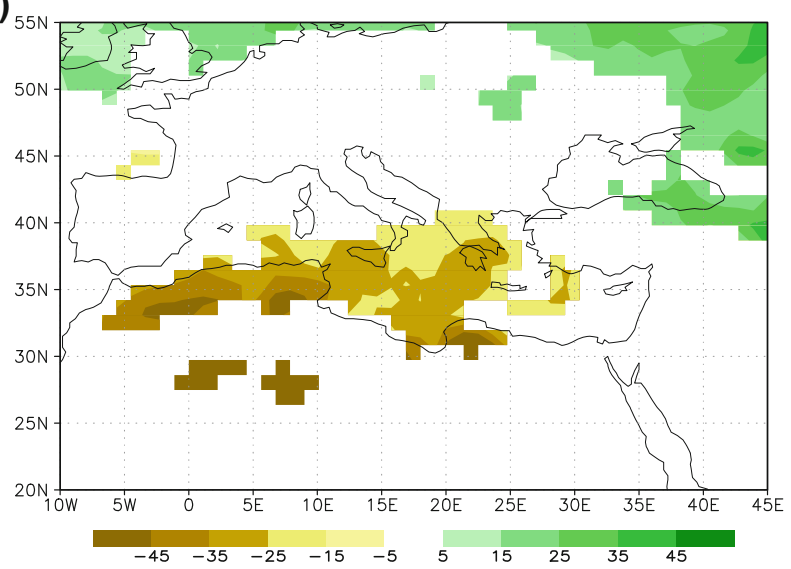

Fig. 11 a Mean winter (DJF) precipitation for the Ctrl simulation (shading interval: $1 \mathrm{~mm} /$ day) and b difference between the A2 (20712100) and the Ctrl simulation (1961-1990). Significant changes at a level of $5 \%$ are shaded in $\mathbf{b}$

\section{Discussion and conclusions}

Winter synoptic-scale features and variability over the MB are investigated for the present day climate and for the end of the twenty-first century. The focus is on the A2 scenario. The MB is located close to the subtropics. Thus, the major climate threat is rain reduction. Moreover, a temperature increase due to increased greenhouse gas concentrations implies enhanced evaporation and thus, aggravation in water shortage and drought risks. As the rainiest season in the MB is the winter, changes in the rainfall in this season would have severe impacts on the hydrological cycle for the entire year.

To investigate future changes of the MB we base our analysis on time-slice simulations of the ECHAM5 model. The comparison between the ERA40 data set and the model simulation for the Ctrl period 1961-1990 shows that the model is capable of reproducing the main synoptic features of the MB in the winter season.

Toward the end of the twenty-first century, the mean atmospheric circulation changes over the MB. An increase in the $500-\mathrm{hPa}$ gph is projected, in particular over the WM, which is related to a stronger temperature increase over that region than over the EM. The upperlevel mean trough shifts from the central to the EM and changes its orientation from northeast-southwest to northsouth. The 1,000-hPa gph exhibits an increase in the gradient from the WM toward the EM in the A2 simulation pointing at a further expansion of the Azores High toward the WM.

The projected reduction of precipitation over the WM is caused by a decrease in the number of cyclones over this region. The decrease in the winter cyclonic activity over the majority of the $\mathrm{MB}$ is explained by changes in various dynamic factors. The baroclinicity illustrated by the maximum Eady growth rate is reduced over the south WM. More important is the fact that the static stability is increased over the entire basin. Another effect is that the area in which kinetic energy of the mean flow is transformed to eddy kinetic energy, shrinks over the Sahara, a region which provides cyclone nuclei for the WM. In addition to the changes in cyclonic activity under A2 scenario, the upper-level stationary wave energy flux diverges over England. This is related to the production of stationary waves in the lower-level troposphere and to a wave train with negative pressure anomalies over the Central Atlantic and positive pressure anomalies over the Caribbean and Central to Eastern Europe. This is a hint that cyclones, which normally travel from the North Atlantic to the WM, tend to be blocked by this increase in stationary wave production in the $\mathrm{A} 2$ simulation.

The EM is projected to behave differently. The baroclinicity is slightly reduced (not significant) and the stability is significantly increased suggesting a reduction in cyclonic activity in the A2 simulation. However, the cyclone activity and the related precipitation over the EM show no significant change for the A2 scenario. A possible reason is that polar intrusions, being an important factor in cyclogenesis over the EM, are found to become more intense. This agrees with the change of the mean atmospheric circulation in the A2 simulation, showing a shift of the main upper trough from the WM to the EM. Both the mean circulation changes and the enhanced intensity of polar intrusions resemble a hypothesis of Graf et al. (1993), who suggested that polar intrusions in the EM intensify under global warming. The dominant factor in this hypothesis is the intensification of the polar night stratospheric jet (PNJ) due to the change in the radiative properties of the stratosphere resulting from greenhouse gases. Indeed, the 
A2 simulation indicates an intensification of the PNJ by $20 \%$ with respect to the Ctrl simulation (not shown). Thus, we conclude that in the A2 simulation the changes in baroclinicity and stability over the EM, which suggest a reduction of cyclones and therefore in precipitation, are compensated by an increase of polar intrusions, with their implied cyclogenesis.

Generally, the reduction of cyclonic activity and precipitation over the MB under A2 scenario agree with previous studies (Schubert et al. 1998; Bengtsson et al. 2006; Pinto et al. 2007; Lionello and Giorgi 2007) and the older set of time-slice simulations (see supplementary material). However, our results concerning the EM are substantially different from those of Giorgi and Lionello (2008). They used the RegCM regional model simulations forced by the HadAM3H of the Hadley Centre and found a decrease in cyclone activity and precipitation over the entire $\mathrm{MB}$, including its eastern part, which is in contrast to our results. As both control simulations (RegCM and ECHAM5 T106 with the higher vertical resolution) realistically reproduce the observed mean precipitation pattern in the Ctrl period (compare Figs. 2 and 11 with Fig. 2 in Lionello and Giorgi (2007) the projection for the EM is highly sensitive to the model used. Comparing our results for the $\mathrm{MB}$ with the observed precipitation trends in the second half of the twentieth century (Alpert et al. 2002) reveal that while most of the drying is observed north of $35^{\circ} \mathrm{N}$, in the A2 simulation the precipitation is reduced south of $35^{\circ} \mathrm{N}$. However, there is some agreement between recent trends and the projected pattern, i.e., Northern Spain experiences a substantial decrease in precipitation.

In order to assess the uncertainty in future climate projections and to separate natural from anthropogenic changes on a spatial scale like the EM, a detailed analysis of the relevant processes (as done in our study) is necessary to be applied on a variety of models and scenarios with sufficiently high resolution. Another step to validate our results can be done by applying our methodology to high resolution models for past periods, like the Maunder Minimum (the period 1645-1715 which is characterized by reduced solar activity and therefore a cold climate condition in Europe) in order to place the anthropogenic induced changes into a broader context of natural variability in the MB (Raible et al. 2007).

Acknowledgments This study was supported by the Israeli Science Foundation (ISF, grant no. 764/06), the European Science Foundation (ESF) within MedCLIVAR, the Research authority of the Open University of Israel, and the National Centre for Competence in Research (NCCR) on Climate funded by the Swiss National Science foundation. Simulations are carried out at the Swiss National Computing Centre (CSCS). The ERA40 reanalysis data were provided by the European Centre for Medium-Range Weather Forecasts (ECMWF).

\section{References}

Alpert P, Reisin T (1986) An early winter polar air mass penetration to the eastern Mediterranean. Mon Weather Rev 114:1411-418

Alpert PB, Ziv B (1989) The Sharav cyclone: observation and some theoretical considerations. J Geophys Res 94:18495-8514

Alpert P, Ben-Gai T, Baharad A, Benjamini Y, Yekutieli D, Colacino M, Diodato L, Ramis C, Homar V, Romero R, Michaelides S, Manes A (2002) The paradoxical increase of Mediterranean extreme daily rainfall in spite of decrease in total values. Geophys Res Lett 29:L1536

Bengtsson L, Hodges KI, Roeckner E (2006) Storm tracks and climate change. J Clim 19:3518-3543

Blackmon ML (1976) A climatological spectral study of the $500 \mathrm{mb}$ geopotential height of the Northern Hemisphere. J Atmos Sci 33:1607-1623

Blender R, Fraedrich K, Lunkeit F (1997) Identification of cyclonetrack regimes in the North Atlantic. Quart J Roy Meteor Soc 123:727-741

Brönnimann S (2007) The impact of El Niño/Southern Oscillation on European climate. Rev Geophys 45:RG3003. doi:10.1029/ 2006RG000199

Christensen JH, Christensen OB (2007) A summary of the PRUDENCE model projections of changes in European climate by the end of this century. Clim Change 81:7-30

Dayan U, Ziv B, Margalit A, Morin E, Sharon D (2001) A severe autumn storm over the Middle-East: synoptic and mesoscale convection. Theo Appl Climatol 69:103-122

Eady ET (1949) Long waves and cyclone waves. Tellus 1:33-52

Gibelin AL, Déqué M (2003) Anthropogenic climate change over the Mediterranean region simulated by a global variable resolution model. Clim Dynam 20:327-339

Giorgi F, Lionello P (2008) Climate change projections for the Mediterranean region. Glob Planet Change 63:90-104. doi: 10.1016/ j.gloplacha.2007.09.005

Graf HF, Kirchner I, Robock A, Schult I (1993) Pinatubo eruption winter climate effects: model versus observation. Clim Dynam 9:81-93

HMSO (1962) Weather in the Mediterranean I: general meteorology, 2nd edn. Her Majesty's Stationery Office, $362 \mathrm{pp}$

Hoskins BJ, James IN, White GH (1983) The shape, propagation and mean-flow interaction of large-scale weather systems. J Atmos Sci 40:1595-1612

IPCC (2001) The scientific basis. In: Contribution of working group I to the third assessment report of the intergovernmental panel on climate change. Cambridge University Press, Cambridge, 881pp

IPCC (2007) The physical science basis. In: Contribution of working group I to the fourth assessment report of the intergovernmental panel on climate change. Cambridge University Press, Cambridge, $976 \mathrm{pp}$

Jacobeit J, Wanner H, Luterbacher J, Beck C, Philipp A, Sturm K (2003) Atmospheric circulation variability in the North-AtlanticEuropean area since the mid-seventeenth century. Clim Dynam. doi:10.1007/s00382-002-0278-0

James IN (1994) Introduction to circulating atmospheres. Cambridge University Press, Cambridge, 422pp

Knippertz P (2005) Tropical-extratropical interactions associated with an Atlantic tropical plume and subtropical jet streak. Mon Weather Rev 133:1-18

Krichak SO, Alpert P (2005) Decadal trends in the east Atlantic-west Russia pattern and Mediterranean precipitation. Int J Climatol 25:183-192

Krichak SO, Alpert P, Bassat K, Kunin P (2007) The surface climatology of the eastern Mediterranean region obtained in a three-member ensemble climate change simulation experiment. Adv Geo Sci 12:67-80 
Lionello P, Giorgi F (2007) Winter precipitation and cyclones in the Mediterranean region: future climate scenarios in a regional simulation. Adv Geo Sci 12:153-158

Lionello P, Malanbotte-Rizzoli P, Boscolo R (2006) Mediterranean climate variability. Developments in earth and environmental sciences, vol 4. Elsevier, Amsterdam, pp 325-372

Mak M, Cai M (1989) Local barotropic instability. J Atmos Sci 46:3289-3311

Martin ML, Luna MY, Morata A, Valero F (2004) North Atlantic teleconnection patterns of low-frequency variability and their links with springtime precipitation in the Western Mediterranean. Int J Climatol 24:213-230

Pinto J, Ulbrich U, Leckebusch G, Spangehl T, Reyers M, Zacharias S (2007) Changes in storm track and cyclone activity in three SRES ensemble experiments with the ECHAM5/MPI-OM1 GCM. Clim Dynam 29:195-210

Plumb RA (1985) On the three-dimensional propagation of stationary waves. J Atmos Sci 42:217-229

Price C, Stone L, Huppert A, Rajagopalan B, Alpert P (1998) A possible link between El Niño and precipitation in Israel. Geophys Res Lett 25:3963-3966

Raible CC (2007) On the relation between extremes of midlatitude cyclones and the atmospheric circulation using ERA40. Geophys Res Lett 34:L07703. doi:10.1029/2006GL029084

Raible CC, Blender R (2004) Midlatitude cyclonic variability in GCM-simulations with different ocean representations. Clim Dynam 22:239-248

Raible CC, Yoshimori M, Stocker TF, Casty C (2007) Extreme midlatitude cyclones and their implications to precipitation and wind speed extremes in simulations of the Maunder Minimum versus present day conditions. Clim Dynam 28:409-423

Raible CC, Della-Marta P, Schwierz C, Wernli H, Blender R (2008) Northern Hemisphere extratropical cyclones: a comparison of detection and tracking methods and different re-analyses. Mon Weather Rev 136:880-897

Rayner NA, Parker DE, Horton EB, Folland CK, Alexander LV, Rowell DP, Kent EC, Kaplan A (2003) Global analyses of sea surface temperature, sea ice, and night marine air temperature since the late nineteenth century. J Geophys Res 108:L4407

Roeckner E, Bäuml G, Bonaventura L, Brokopf R, Esch M, Giorgetta M, Hagemann S, Kirchner I, Kornblueh L, Manzini E, Rhodin A, Schlese U, Schulzweida U, Tompkins A (2003) The atmospheric general circulation model ECHAM5: part I: model description. Technical Report 349, Max-Planck-Institute, Hamburg, 127 pp

Romem M, Ziv B, Saaroni H (2007) Scenarios in the development of Mediterranean cyclones. Adv Geosci 12:59-65

Rowell DP (2005) A scenario of European climate change for the late twenty-first century: Seasonal means and interannual variability. Clim Dynam 25:837-849

Rubin S, Ziv B, Paldor N (2007) Tropical Plumes over eastern North Africa as a source of rain in the Middle East. Mon Weather Rev 35:4135-4148

Saaroni H, Bitan A, Alpert P, Ziv B (1996) Continental polar outbreaks into the Levant and eastern Mediterranean. Int J Climatol 16:1175-1191

Schubert M, Perlwitz J, Blender R, Fraedrich K, Lunkeit F (1998) North Atlantic cyclones in $\mathrm{CO}_{2}$-induced warm climate simulations: Frequency, intensity, and tracks. Clim Dynam 14:827-838

Trenberth KE (1986) An assessment of the impact of transient eddies on the zonal flow during a blocking episode using localized Eliassen-Palm flux diagnostics. J Atmos Sci 43:2070-2087

Uppala SM, Kallberg PW, Simmons AJ et al (2005) The ERA40 reanalysis. Quart J Roy Meteor Soc 131:2962-3012

Walland D, Simmonds I (1999) Baroclinicity, meridional temperature gradient, and the Southern Semiannual Oscillation. J Clim 12:3376-3382

Wilks DS (2006) Statistical methods in the atmospheric sciences, 2nd edn. Academic, London, 627 pp

Ziv B (2001) A subtropical rainstorm associated with a tropical plume over Africa and the Middle-East. Theor Appl Clim 69:91-102

Ziv B, Dayan U, Kushnir Y, Roth C, Enzel Y (2006) Regional and global atmospheric patterns governing rainfall in the Southern Levant. Int J Climatol 26:55-73 